\title{
Cidadania cultural, tecnologia assistiva e pessoa com deficiência
}

DOI: https://doi.org/10.22409/pragmatizes.v10i19.42436

\author{
Patrícia Silva Dorneles ${ }^{1}$ \\ Cláudia Reinoso Araujo de Carvalho ${ }^{2}$ \\ Eduardo Cardoso ${ }^{3}$ \\ Jefferson Fernandes Alves ${ }^{4}$ \\ Miryam Bonadiu Pelosi ${ }^{5}$
}

\begin{abstract}
Resumo: Nos últimos anos, a inclusão dos recursos de acessibilidade em produtos, projetos e programas artísticos culturais tem se ampliado como exigência em políticas de fomento a fim de garantir o direito cultural das pessoas com deficiência. Tais exigências são resultado da luta política no âmbito cultural de diferentes atores, pessoas com deficiência ou não, que atuam nas áreas da produção artística e nos campos da cultura e dos direitos humanos. O cenário destas conquistas compõe os processos políticos de democratização da cultura, a inserção do direito cultural e da diversidade como eixo estruturante das políticas culturais contemporâneas, e ainda em desafio, o fortalecimento da perspectiva da inclusão a partir do modelo social da deficiência. Neste contexto, a efetivação da legislação no campo cultural na perspectiva da acessibilidade para o público de pessoas com deficiência provocou deslocamentos de áreas e aproximação de saberes a fim de inter
\end{abstract}

\footnotetext{
${ }^{1}$ Patrícia Silva Dorneles. Doutora em Geografia pela Universidade Federal do Rio Grande do Sul, professora do Departamento de Terapia Ocupacional da Faculdade de Medicina da Universidade Federal do Rio de Janeiro - UFRJ, Brasil. E-mail: patricia.dorneles.ufrj@gmail.com https://orcid.org/0000-0003-3440-7549

${ }^{2}$ Claudia Reinoso Araujo de Carvalho. Doutora em Saúde Pública pela Fundação Oswaldo Cruz. Professora do Departamento de Terapia Ocupacional da Faculdade de Medicina da Universidade Federal do Rio de Janeiro - UFRJ, Brasil. E-mail: claudiareinoso@ufrj.br - https://orcid.org/0000-00034105-9191

${ }^{3}$ Eduardo Cardoso. Doutor em Design pela Universidade Federal do Rio Grande do Sul - UFRGS, professor da Faculdade de Arquitetura da UFRGS, Brasil. E-mail: eduardo.cardoso@ufrgs.br https://orcid.org/0000-0002-1202-1779

${ }^{4}$ Jefferson Fernandes Alves. Doutor em Educação pela Universidade Federal do Rio Grande do Norte, UFRN, professor do Centro de Educação da UFRN, Brasil. E-mail: jeffersonfernandes248@gmail.com - https://orcid.org/0000-0003-0808-7115

${ }^{5}$ Miryam Bonadiu Pelosi. Doutora em Educação pela Universidade do Estado do Rio de Janeiro UERJ, professora do Departamento de Terapia Ocupacional da Faculdade de Medicina da Universidade Federal do Rio de Janeiro - UFRJ, Brasil. E-mail: miryampelosi@ufrj.br http://orcid.org/0000-0002-6109-4296
} 


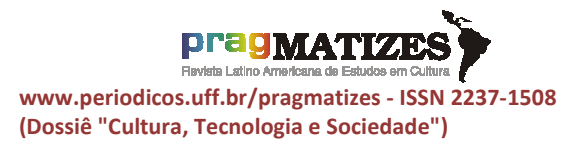

(Dossiê "Cultura, Tecnologia e Sociedade")

e transdisciplinar buscar soluções tecnológicas que qualifiquem a mediação e a fruição estética deste público. Este artigo tem como objetivo apresentar um breve contexto da pauta da cidadania cultural das pessoas com deficiência no âmbito das políticas culturais, o papel da universidade pública na qualificação do campo, a inserção dos recursos e serviços de tecnologia assistiva nos ambientes culturais e os desafios da qualificação das políticas culturais para pessoas com deficiência.

Palavras Chaves: Cultura; Políticas Culturais; Direitos humanos; Acessibilidade Cultural.

\title{
Ciudadanía cultural, tecnología asistencial y personas con discapacidad
}

Resumen: En los últimos años, la inclusión de recursos de accesibilidad en productos, proyectos y programas artísticos culturales se ha ampliado como un requisito en las políticas de desarrollo para garantizar el derecho cultural de las personas con discapacidad. Tales demandas son el resultado de la lucha política en la esfera cultural de diferentes actores, personas con discapacidad o no, que trabajan en las áreas de producción artística y en los campos de la cultura y los derechos humanos. El escenario de estos logros compone los procesos políticos de democratización de la cultura, la inserción del derecho cultural y la diversidad como eje estructurante de las políticas culturales contemporáneas, y aún desafía el fortalecimiento de la perspectiva de inclusión basada en el modelo social de discapacidad. En este contexto, la implementación de la legislación en el campo cultural en la perspectiva de accesibilidad para el público de las personas con discapacidad provocó el desplazamiento de áreas y la aproximación del conocimiento para encontrar soluciones tecnológicas interdisciplinarias que califiquen la mediación y el disfrute estético de esta audiencia. Este artículo tiene como objetivo presentar un breve contexto de la agenda de ciudadanía cultural de las personas con discapacidad dentro del alcance de las políticas culturales, el papel de la universidad pública en la calificación del campo, la inserción de tecnologías de asistencia en entornos culturales y los desafíos de las políticas culturales calificadas para personas con discapacidad.

Palabras clave: Cultura; Políticas culturales; Derechos humanos; Accesibilidad Cultural.

\section{Cultural citizenship, assistive technology and people with disabilities}

\begin{abstract}
In recent years, the inclusion of accessibility resources in products, projects and cultural artistic programs has expanded as a requirement in development policies in order to guarantee the cultural right of people with disabilities. Such demands are the result of the political struggle in the cultural sphere of different actors, people with disabilities or not, who work in the areas of artistic production and in the fields of culture and human rights. The scenario of these achievements is part of the political processes of democratization of culture, the insertion of cultural law and diversity as a structuring axis of contemporary cultural policies, and still in challenge the strengthening of the perspective of inclusion from the social model of disability. In this context, the implementation of legislation in the cultural field in the perspective of accessibility for the public of people with disabilities caused displacement of areas and approximation of knowledge in order to inter and trans disciplinary technological solutions that qualify the mediation and aesthetic enjoyment of this public. This article aims to present a brief context of the agenda of cultural citizenship of people with disabilities within the scope of cultural policies, the role of the public university in the qualification of the field, the insertion of assistive technologies in cultural environments and the challenges of qualifying cultural policies for people with disabilities.
\end{abstract}

Keywords: Culture; Cultural Policies; Human Rights; Cultural Accessibility. 


\section{Cidadania cultural, tecnologia assistiva e pessoa com deficiência}

\section{Introdução}

Como parte da Cidadania Cultural, a pauta da acessibilidade cultural para pessoas com deficiência é recente junto às políticas, projetos, programas e ações culturais. Ainda assim, a legislação brasileira mostrase, de certa forma, abrangente na garantia dos direitos culturais da pessoa com deficiência, pois, verificase que o tema está presente em diversos dispositivos constitucionais e legais. Contudo, não obstante os avanços na legislação, ainda se observa certa disparidade entre o que diz a lei e a prática, bem como persistem os desafios atuais da qualificação e fortalecimento da pauta junto às políticas públicas, o que exige um esforço intersetorial (DORNELES; CARVALHO; MEFANO, 2019).

$$
\text { Enquanto campo em }
$$

construção, a acessibilidade cultural deve ser inicialmente compreendida como o direito de vivenciar experiências de fruição cultural com igualdade de oportunidades para diversos públicos, entre eles, pessoas com deficiência e mobilidade reduzida.
Para se promover a inclusão de pessoas com deficiência nos espaços culturais é necessário garantir que qualquer pessoa que tenha o desejo de se beneficiar de tais equipamentos não seja excluída por conta de diferentes formas de locomoção, cognição e percepção. Desta forma, a "acessibilidade nos espaços culturais pressupõe o desenvolvimento de novas estratégias de mediação, nas quais todos os sentidos inerentes à percepção sejam envolvidos" (SARRAF, 2012, p.68).

Este artigo tem como objetivo apresentar e discutir a pauta da cidadania cultural das pessoas com deficiência no âmbito das políticas culturais. Para isso, apresenta-se um breve contexto da construção histórica recente dessa pauta, aborda-se 0 papel da universidade pública na qualificação do campo em construção, a inserção dos recursos e serviços de tecnologia assistiva em ambientes e produtos culturais, bem como os desafios inerentes à qualificação das políticas culturais para pessoas com deficiência. 


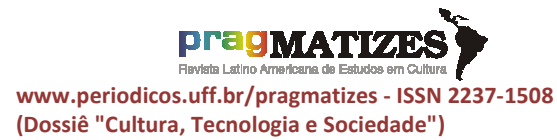

(Dossiê "Cultura, Tecnologia e Sociedade")

\section{Cidadania cultural das pessoas com} deficiência no âmbito das políticas culturais

Em outubro 2008, a então Secretaria de Identidade e Diversidade Cultural - SID, do Ministério da Cultura - MinC realizou, em parceria com a Fundação Oswaldo Cruz - Fiocruz, a Oficina Nacional de Indicação de Políticas Públicas Culturais para Pessoas com Deficiência. Tal iniciativa representou 0 processo de institucionalização da política de acessibilidade cultural junto ao governo federal.

Embora, no âmbito do MinC, por meio da Fundação Nacional das Artes - FUNARTE- RJ já existisse uma ação de fomento e difusão da produção estética, artística e cultural de pessoas com deficiência, em parceria com a organização brasileira Arte sem Barreiras, foi na referida oficinapromovida pela SID que a pauta acessibilidade no sentido de direito cultural da pessoa com deficiência à fruição estética surgiu como demanda do movimento social para que tal direito fosse institucionalizado junto às políticas públicas de cultura (DORNELES; CARVALHO; MEFANO, 2019). Foi justamente a pauta da acessibilidade que provocou os deslocamentose aproximações entre as áreas e saberes a fim de a buscar,inter e transdisciplinarmente, as soluções tecnológicas visando qualificar a mediação e a fruição estética deste público.

A SID foi constituída em 2004 com o objetivo de elaborar e implementar uma política que assegurasse a todos os segmentos da sociedade a possibilidade de produzir e difundir suas manifestações culturais em diferentes escalas. A realização de oficinas temáticas junto a alguns segmentos da diversidade cultural compôs um conjunto de iniciativas metodológicas de aproximação com o público alvo da secretaria e suas demandas para as políticas culturais. Embora o Brasil tenha se tornado signatário da Convenção da Diversidade Cultural desde 2007, sabe-se que a partir de 2003, na gestão do ministro da cultura Gilberto Gil, o governo brasileiro desenvolveu uma política de cultura baseada no conceito amplo de cultura dedicado, então, a toda a sociedade e rompendo com a perspectiva das gestões anteriores que estruturava-se para atender às artes e outros segmentos 
da cultura não atendidos pelo mecanismo de renúncia fiscal (DUPIN, 2015).

Nesta perspectiva, a Oficina Nacional de Indicação de Políticas Públicas Culturais para a Inclusão de Pessoas com Deficiência foi realizada com a participação de mais de 60 pessoas envolvidas com o tema, de diferentes regiões do país e de representatividade institucional, composta por colaboradores ativos, pessoas com deficiência ou não, que atuavam, no período, no campo da produção artística de pessoas com deficiência, ou, que já estavam envolvidas com a temática da acessibilidade cultural no que diz respeito ao direito da fruição estética da pessoa com deficiência em relação aos diferentes produtos culturais. Por ser uma oficina com o princípio de escutar o setor (DUPIN, 2015) e sistematizar por meio de grupos de trabalhos ações e diretrizes visandoorientar a constituição de uma política cultural para o mesmo, o grupo participante sugeriu que a publicação do relatório final e a própria oficina fosse denominada com o lema de luta das pessoas com deficiência, "Nada sobre nós sem nós", como tal é reconhecida até hoje. Cabe destacar que a oficina foi realizada no mesmo ano que o Brasil se tornou signatário da Convenção dos Direitos das Pessoas com Deficiência, e a mesma tornou-se um dos resultados dos compromissos do MinC à demanda latente da sociedade civil que atuava no campo da produção e difusão artística e cultural das pessoas com deficiência.

É importante ressaltar a significativa contribuição do grupo articulado do movimento Artes sem Barreiras no que se refere a sistematização e articulação da demanda da sociedade civil em relação à pauta de uma política cultural para a produção estética e artística das pessoas com deficiência, incluindo a pauta da acessibilidade cultural junto ao MinC.

O "Arte sem Barreiras", nos anos 90, reuniu um grupo de artistas e profissionais com ou sem deficiência de diferentes áreas das artes, e se constituiu como um trabalho articulado em rede nacional de forma voluntária com o objetivo de mapear iniciativas e produções artísticas para articular fomento, difusão e qualificação profissional dos grupos e indivíduos 
envolvidos com o direito cultural das pessoas com deficiência. Esta rede, inicialmente foi fomentada a partir da Fundação Nacional das Artes FUNARTE/RJ através de uma figura preciosa ao grupo, senhora Albertina Brasil. Funcionária de carreira da instituição, Albertina, sensibilizada por experiências internacionais da associação Very Special Arts - VSA iniciou um trabalho no Brasil instituindo na ocasião o Programa Arte sem Barreiras na FUNARTE/RJ em parceria com diferentes atores do campo da produção cultural e artística junto a pessoas com deficiência (DORNELES; CARVALHO; SILVA; MEFANO, 2018). O VSA é umprograma criado em 1974 pela Sra. Jean Kennedy Smith no Kennedy Center Performing Arts, em Washington, D.C., com o objetivo de possibilitar o desenvolvimento da capacidade de criação da pessoa com deficiência.

O Programa Arte sem Barreiras se desenvolveu com pouco apoio do MinC, mas encontrou algum acolhimento nas iniciativas do Ministério da Educação - MEC em relação a promoção dos encontros nacionais de arte-educação. Nestes encontros, Albertina e colegas da FUNARTE com um considerável grupo de representantes de diferentes entidades de arte e da educação inclusiva constituem o comitê no Brasil do Programa Very Special Arts. Este comitê, associado à rede internacional do mesmo nomefoi formado em 1998, e realizou em maio do mesmo ano em parceria com o Serviço Social do Comércio - SESC/SP o "1 Festival Latino-Americano de Artes sem Barreiras" e o "1ํ Congresso LatinoAmericano de Arte-Educação Inclusiva". A partir de então uma agenda intensa e de articulação nacional foi desenvolvida com 0 objetivo de articulação, capacitação e difusão em prol da valorização da produção estético artística das pessoas com deficiência no Brasil.

O resultado potente deste trabalho, associado às orientações dos grupos internacionais foi a formação de representações regionais do Arte sem Barreiras. As representações regionais da associação serviram de base de mobilização e articulação local e nacional de diferentes intercâmbios deste trabalho em rede e da realização dos Festivais Artes sem Barreiras. Como resultados da atuação deste 


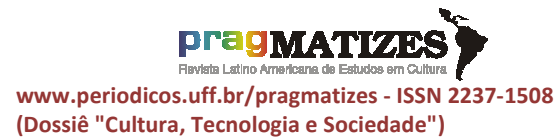

(Dossiê "Cultura, Tecnologia e Sociedade") grupo, entre tantos outros, observa-se a visibilidade da produção estética e artística da pessoa com deficiência, a rica troca de experiências e a qualidade do trabalho em rede, o fortalecimento do campo político da cidadania cultural das pessoas com deficiência, a construção da rede nacional Artes sem Barreiras e seus núcleos específicos de dança, teatro, artes visuais entre outros. O legado cultural e artístico para a diversidade da cultura brasileira, identificado na contribuição da produção estética e artística das pessoas com deficiência nas políticas culturais, se deve a este grupo e ao seu trabalho.

A separação institucional da ONG Artes sem Barreiras com a FUNARTE/RJ ocorreu nos anos 2000.

O grupo Arte sem Barreiras buscou novos apoios para dar continuidade às suas ações. A gestão da FUNARTE/RJ do ano de 2006, atendendo as demandas do grupo e de outros militantes da pauta, realizou com o apoio da Caixa Econômica Federal o edital Além dos Limites que apoiou iniciativas, indivíduos, promoveu debates e a qualificação e circulação dos projetos artísticos premiados. No fim de 2007, a
FUNARTE passou a política de cultura para pessoas com deficiência para SID. Umas das razões da transferência da pauta para a SID é que esta secretaria iniciou uma política nacional de cultura dedicada às ações e expressões culturais e artísticas que se encontravam no grupo das pessoas com sofrimento psíquico e ou transtorno mental. A SID em parceria com a FIOCRUZ, realizou em 2007 a Oficina Nacional de Políticas Culturais para pessoas em sofrimento psíquico e vulnerabilidade social, chamada Loucos pela Diversidade. Em 2008, as duas instituições lançaram o edital de premiação "Loucos pela Diversidade", que homenageou 0 autor do livro Bicho de Sete Cabeças - Austregésilo Carrano.

No exercício das políticas públicas culturais neste período se observava ainda um olhar restrito sobre acessibilidade cultural para pessoas com deficiência. A perspectiva limitada reduzindoà acessibilidade física do espaço e não do produto ou objeto cultural foi rompida a partir da Oficina "Nada sobre nós sem nós". A oficina teve como objetivo escutar, conhecer e sistematizar as experiências no campo 


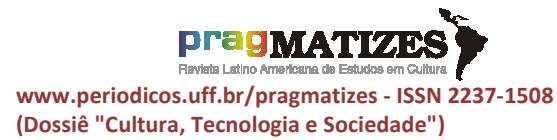

(Dossiê "Cultura, Tecnologia e Sociedade") da interface de políticas e produção estética, artística e cultural das/e para as pessoas com deficiência; construir, a partir dos Grupos de Trabalho sobre o fomento, patrimônio, difusão e acessibilidade, ações e diretrizes orientadoras para uma política pública cultural para pessoas com deficiência. A inclusão do GT Acessibilidade foi o que fez a diferença desta oficina em relação às outras organizadas pela SID para construção de políticas públicas culturais. Entre os resultados, destacaram-se a ampliação e o fortalecimento do debate sobre o tema e o direito da cidadania cultural da pessoa com deficiência nas conferências municipais, estaduais e nacional de cultura. (DORNELES; CARVALHO; SILVA, 2017)

Somando as ações e diretrizes para uma política pública cultural para pessoas com deficiência, registra-se também na publicação dos resultados da Oficina Nada sobre nós sem nós, a nota técnica no 001/2009 que apresentou: a necessidade de incorporação da política de acessibilidade na Lei Rouanet, nos sites e editais do MinC de forma geral; a importância da implementação de uma política de livro acessível; a incorporação da acessibilidade nas produções culturais do órgão e 0 diálogo com os outros ministérios para ampliar a articulação interinstitucional para a implementação das políticas de fomento, difusão, patrimônio e acessibilidade junto às produções estéticas e artísticas das pessoas com deficiência. Percebeu-se também a necessidade de ampliar o conceito de acessibilidade cultural até então utilizado pelo MinC que se reduzia a perspectiva de gratuidade e de valores acessíveis para espetáculos e outros produtos culturais beneficiados pela Lei Rouanet. Assim, se torna função do MinC a partir da oficina, o compromisso de orientar e fomentar a aplicabilidade de acessibilidade cultural nas políticas e gestões públicas culturais, no que diz respeito ao direito de fruição estética, ampliando os formatos de acessibilidade dos diversos produtos culturais.

A partir da oficina, registraramse novas iniciativas do MinC em relação a acessibilidade cultural. Em 2010 a Secretaria do Audiovisual, através da Programadora Brasil incluiu 30 filmes com audiodescrição que fazem parte dos kits distribuídos pelo 
programa. No ano seguinte, o MinC lançou o edital Prêmio Arte e Cultura Inclusiva Albertina Brasil para 30 iniciativas culturais. Em 2012 o Instituto Brasileiro de Museus - IBRAM lançou o Cadernos Museológicos 2 com o tema especial Acessibilidade a Museus.

Em 2013 a pauta da acessibilidade cultural tornou-se mais fortalecida. O MinC publicou a Instrução Normativa - IN da Lei Rouanet que previu medidas de acessibilidade cultural. Hoje novas INs na lei vêm qualificando a inserção dos recursos de acessibilidade nos projetos que pretendem ser beneficiados pela lei. No mesmo ano, em parceria com a UFRJ o MinC realizou a primeira turma do Curso de Especialização em Acessibilidade Cultural em um projeto que se estende por quase uma década, com diferentes iniciativas de formação e difusão da pauta. Ainda em 2013 ocorreu a inclusão da rubrica de acessibilidade cultural nos editais dos Pontos de Cultura, de valor de $2 \%$ à $5 \%$ do total do projeto cultural do Ponto, e em 19 de setembro do mesmo ano lançou-se - Dia Nacional do Teatro Acessível pelo então Deputado Federal Jean
Willys em parceria com a Escola de Gente/ RJ (Projeto de Lei 129/2013). A criação do Grupo de Trabalho Interministerial de Acessibilidade: GTI SCDC/MinC e Secretaria de Direitos Humanos da Presidência da República $\mathrm{SDH} / \mathrm{PR} ; \quad$ e 0 edital projeto Acessibilidade em Bibliotecas Públicas, parceria MinC e a instituição Mais Diferença também foram desenvolvidos no mesmo período.

No ano de 2014 a Agência Nacional de Cinema - Ancine estabeleceu a Instrução Normativa - IN 116 obrigando a inclusão de recursos de acessibilidade nas cópias das obras audiovisuais fomentadas com recursos públicos federais. Também foi previsto que todos os projetos apresentados à agência que utilizassem recursos de renúncia fiscal ou do Prêmio Adicional de Renda deveriam incluir os recursos de legendagem, legendagem descritiva, audiodescrição e Libras. Esta medida ocasionou que praticamente a totalidade do conteúdo audiovisual brasileiro voltado ao segmento de exibição cinematográfica passasse a contar com os recursos de acessibilidade. Cabe destacar que a Ancine, desde 2015, passou a incluir em editais que empregam recursos do 


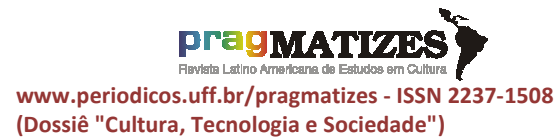

(Dossiê "Cultura, Tecnologia e Sociedade")
Fundo Setorial do Audiovisual a obrigatoriedade dos recursos de acessibilidade. Nesse sentido as INs $132 / 2017$ e 145/2018 qualificaram a IN 116/2014.

Em 2015, o Brasil aprovou o Tratado de Marraqueche na forma qualificada prevista no $\S 3^{\circ}$ do artigo $5^{\circ}$ da Constituição Federal, conforme o Projeto de Decreto Legislativo 347/2015 do Senado Federal (57/2015, na Câmara dos Deputados). O Tratado de Marraqueche tem como objetivo facilitar 0 acesso a obras publicadas a pessoas cegas, com deficiência visual ou com outras dificuldades para ter acesso ao texto impresso.

A Secretaria de Audiovisual do MinC lançou em 2016 em parceria com a Universidade de Brasília - UnB e parceiros, o Guia de Produções Audiovisuais Acessíveis com o objetivo de trazer parâmetros para os recursos de acessibilidade para que todos os envolvidos com a produção audiovisual pudessem seguir um padrão de qualidade de maneira a atender a comunidade de pessoas com deficiência visual e auditiva.

No âmbito dos Museus não há até 0 momento uma orientação específica, mas observa-se o crescente de ações acessíveis nestes ambientes culturais. As iniciativas se baseiam nas orientações do Estatuto dos Museus - lei 11904/2009 que orientam a universalidade e a importância de um plano museológico de acessibilidade, e a IN IPHAN $\mathrm{n}^{\circ}$ 1/2003.

A pauta da acessibilidade cultural é destacada no Plano Nacional de Cultura - PNCdesde 2010, através da meta 29, que nos desafia a atingir "100\% de bibliotecas públicas, museus, cinemas, teatros, arquivos públicos e centros culturais atendendo aos requisitos legais de acessibilidade e desenvolvendo ações de promoção da fruição cultural por parte das pessoas com deficiência".Sobre 0 acompanhamento do PNC observa-se que os Museus têm ampliado os quesitos de acessibilidade física (MINISTÉRIO DA CULTURA, 2010). Atualmente Secretaria de Cidadania e Diversidade Cultural - SCDC tem realizado algumas iniciativas que contemplam a população com deficiência, como o caso do Edital de Cultura Populares de 2018 e o apoio ao VI e VII Encontro Nacional de Acessibilidade Cultural - ENAC. 


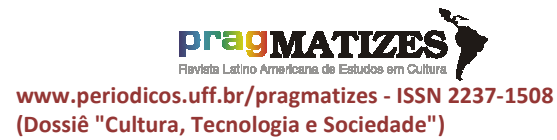

(Dossiê "Cultura, Tecnologia e Sociedade")
$\mathrm{Na}$ atual conjuntura política brasileira, observamos desde 2016 uma situação bastante adversa para a cultura, bem como as questões dos direitos das pessoas com deficiência, implicando em uma fragilidade na continuidade e no desmonte de importantes ações. As conquistas anteriores que representam um processo, ainda permanecem vivas na pauta dos atores que atuam em prol da cidadania cultural das pessoas com deficiência.

\section{Contribuições da Universidade} Pública para a Cidadania Cultural das Pessoas Com Deficiência

Como parte importante do esforço intersetorial da pauta da promoção da acessibilidade cultural encontra-se a universidade, que pode mobilizar todo ciclo dinâmico da cultura, dada a sua complexidade. A universidade, no âmbito da cultura, pode atuar na: criação, transmissão, difusão, distribuição, veiculação, preservação, consumo, pesquisa, crítica, curadoria, organização e legitimação.

Nas Universidades as manifestações culturais e a expressão de linguagens artísticas das mais variadas

encontram

espaço, conferindo, de certa maneira, um terreno no qual o pensamento reflexivo costuma envolver muitas vezes a formação de sujeitos com um olhar mais permeável à diversidade, à diferença, à inclusão e ao acolhimento de visões alternativas sobre o mundo (FRANÇA JUNIOR;

LIMA; RODRIGUES, 2018). No entanto, a atuação das universidades, em se tratando das ações culturais, não têm se dado em todo o seu potencial devido ao desconhecimento, desarticulação e redundância das ações (RUBIM, 2019). Para qualificar o papel da universidade na relação com a cultura e sua contribuição com as políticas culturais nos últimos anos observou-se a sua qualificação através da constituição depolíticas ou planos de cultura. A Universidade Federal do Rio de Janeiro - UFRJ tem pioneirismo neste processo, incluído a acessibilidade cultural como uma meta. A Universidade Federal do Rio Grande do Norte - UFRN e a Universidade Federal do Rio Grande do Sul - UFRGS têm estruturado ações identificadas com a constituição de seus planos e políticas culturais. 


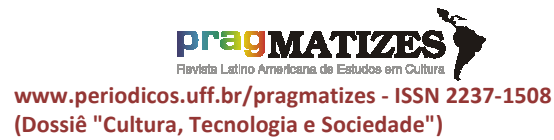

Os contextos de formação inicial e continuada, sob o protagonismo das universidades, no que se refere aos diversos campos profissionais, em especial aqueles que se orientam diretamente pelas esferas da cultura e da educação, são carentes de experiências curriculares em torno das temáticas da acessibilidade e da inclusão. Os componentes ofertados, tais como LIBRAS e fundamentos ou noções da educação especial na perspectiva inclusiva, são insuficientes para o enfrentamento das demandas contemporâneas de formação das diversas profissões que precisam considerar novos desenhos de profissionalidadee de profissionalização, levando em conta a perspectiva da reinvenção social a partir da consideração das pessoas com deficiência ou com formas singulares de ser e de estar no mundo como protagonistas culturais.

O Curso de Especialização em Acessibilidade Cultural da UFRJ tem colaborado no sentido de promover capacitação no nível lato sensu no que diz respeito ao uso de tecnologia assistiva como instrumento de mediação para a fruição estética, e para a constituição e fortalecimento de uma rede de formação em acessibilidade cultural nacional e internacional de caráter interdisciplinar. Este curso de pósgraduação é uma iniciativa única de formação sobre o tema em nível de lato sensu na América Latina com enfoque inter e transdisciplinar. O projeto surgiu, em 2010, inspirado nas demandas e nas necessidades de capacitação e formação, tendo como referência os direitos culturais da pessoa com deficiência e é dirigido a gestores públicos de cultura, Pontos de Cultura, professores universitários, representantes do terceiro setor e produtores culturais.

A acessibilidade cultural é um campo em construção, complexo e interdisciplinar. O domínio das tecnologias para a aplicabilidade da acessibilidade cultural encontra-se centrado na iniciativa privada, que lhe garante um mercado e uma sustentabilidade, a partir de consultorias, prestações de serviços e formação. As universidades públicas brasileiras ainda abordam timidamente essa temática e faz-se urgente a constituição de um campo. As poucas iniciativas de formação e pesquisa nas universidades parecem partir de ações 
isoladas e solitárias de alguns professores e técnicos e na sua grande maioria se direcionam para uma única linguagem de mediação, um único formato de comunicação acessível específico para um tipo de deficiência (DORNELES; CARVALHO; CASTRO, 2017).

O curso embasa-se fortemente na legislação pertinente ao campo dos direitos sociais, culturais e aos direitos da pessoa com deficiência. A proposta da formação em acessibilidade cultural da UFRJ configura-se como uma formação acadêmica e de ação cultural, identificada com a concepção de Freire (1981) para quem ação cultural é ação política, isto é, ação coletiva e engajada. Assim, ela se caracteriza pelo "diálogo libertador, que promove conhecimento e práxis, comunhão de sujeitos participantes da transformação da realidade" (FREIRE, 1981, p. 85). Portanto, na perspectiva do curso, cada aluno deve tornar-se um multiplicador de conhecimento e um ator político-social de promoção da política pública de acessibilidade cultural para pessoas com deficiência. Desenvolve-se uma metodologia da implicação, caracterizada pelo compromisso político da aplicabilidade do conhecimento adquirido, da difusão e da reflexão sobre a prática, pretendendo a implementação de metodologias ativas capazes de construir programas de sensibilização e políticas de institucionalização para a pauta.

A matriz curricular da Curso é composta por 12 disciplinas: Política e Diversidade Cultural, Aspectos Gerais das Deficiências, Tecnologia Assistiva I, Tecnologia Assistiva II, Audiodescrição I, Audiodescrição II, Exposição Acessível I, Exposição Acessível II, Braile e outros recursos, Sensibilização em Libras, Seminário de Projeto I e Seminário de Projeto II.

A formação profissional dos alunos foi diversificada, ao longo das três edições do curso, o que contribuiu para uma produção científica com diferentes enfoques. Entre os temas dos trabalhos finais destacam-se: políticas culturais, a acessibilidade nos Pontos de Cultura, a acessibilidade em equipamentos culturais, a formação profissional, os recursos de acessibilidade, e acessibilidade no contexto da deficiência, entre outros.

No projeto de formação ainda se associa a realização do Encontro Nacional de Acessibilidade Cultural - 
ENAC, que em 2019 chegou a 7a edição. Os ENAC têm contribuído para a construção da política cultural de acessibilidade. Cabe destacar que o I ENAC foi realizado em 2013 em parceria com a UFRGS que somou a sua iniciativa de realizar o II Seminário Nacional de Acessibilidade em Ambientes Culturais - SENAC. Junto a esta iniciativa realizou-se a Conferência Livre em Acessibilidade Cultural que apresentou 90 propostas para última Conferência Nacional de Cultura, aprovando como prioritária a proposta 3.18 do eixo 4.Entre o exalunos, alguns foram delegados nas conferências municipais, estaduais e nacional de cultura, o que confere o sucesso da metodologia empregada. No II ENAC realizado em 2014 em parceria com a UFRGS e a UFRN como uma atividade do TEIA Encontro Nacional dos Pontos de Cultura se constituiu o GT de Acessibilidade Cultural dos Pontos de Cultura e a circulação do abaixo assinado, hoje legislação, da inclusão da janela de libras na produção audiovisual brasileira.

Desde sua proposição inicial, a especialização em acessibilidade cultural se orientou pela perspectiva de aglutinar pesquisadores de outras universidades, tendo como referência a necessidade de que esta pauta emergisse no ambiente universitário e que permitisse a convergência de esforços interinstitucionais. De fato, a questão da acessibilidade manifestase no contexto universitário em íntima relação com a Tecnologia Assistiva e com a Educação Especial. No entanto, sua qualificação para os múltiplos cenários artísticos e culturais é algo recente e ainda incipiente. Verificamse esforços investigativos articulados na Universidade Estadual do Ceará (UECE), com o Grupo LEAD (Legendagem e Audiodescrição), na Universidade Federal da Bahia, com o Grupo TRAMAD (Tradução, Mídia e Audiodescrição) e iniciativas de pesquisadores em outras universidades. Do ponto de vista formativo, é recorrente a oferta de cursos de extensão, sobretudo, em audiodescrição. Destacam-se, nesse sentido, as iniciativas de pósgraduação (especialização) em audiodescrição da Universidade Federal de Juiz de Fora (UFJF) e da UECE, sendo que essa última universidade também ofereceu uma especialização em Legendagem para 
Surdos e Ensurdecidos, ambas as formações na modalidade EAD. Ainda cabe ressaltar as disciplinas de acessibilidade cultural que estão sendo constituída em diferentes cursos de graduação a partir de discentes da pós-graduaçãoda UFRJ multiplicando a pauta.Entre elas podemos destacar a disciplina "Acessibilidade Cultural" no Curso de

Terapia Ocupacional,"Gastronomia Acessível" no curso de Gastronomia da UFRJ, "Teatro Acessível" no curso de Teatro da Universidade Federal do Amapá UNIFAP, e a disciplina "Produção Cultural Acessível" no Instituto Federal do Rio de Janeiro.

Em vista disso, foi sendo delineada uma rede de articulação envolvendo a UFRJ, a UFRGS e a UFRN em torno da temática da Acessibilidade Cultural em favor de ações convergentes que mobilizassem asuniversidades públicas na consolidação dessa temática, considerando a observância dos direitos culturais da pessoa com deficiência. Além de identificação e estabelecimento de interlocução com pesquisadores de outras instituições públicas de ensino superior, almeja-se a constituição de uma plataforma de formação continuada que possa ampliar a capacidade de ofertas formativas, considerando a dimensão continental do Brasil. Para tanto, é fundamental o delineamento de ações investigativas compartilhadas que permitam a construção e socialização de saberes, procedimentos e tecnologia assistiva que concorram para a consecução dos objetivos da acessibilidade cultural.

\section{Da Tecnologia assistiva}

As definições mundiais sobre Tecnologia Assistiva relacionadas às políticas públicas, às classificações de saúde, de educação e de movimentos sociais têm sido atualizadas e modificadas constantemente, com 0 intuito de contemplar as demandas da população mundial.

No Brasil, o desenvolvimento da área de Tecnologia Assistiva, a partir da ótica das políticas públicas, teve marcos importantes nas áreas da educação e saúde. Entre elas destacam-se: o Programa de Implantação de Salas de Recursos Multifuncionais, que levou para a escola um conjunto de recursos de Tecnologia Assistiva (BRASIL, 2007); o Programa de Formação continuada 
de Professores na Educação Especial com 0 objetivo de favorecer 0 desenvolvimento de práticas pedagógicas inclusivas apoiadas pelos recursos de TA (BRASIL, 2014a); 0 Programa de Assistência à Pessoa com Deficiência em 2008, que compreendeu um conjunto de políticas públicas estruturadas em quatro eixos: Acesso à Educação, Inclusão social, Atenção à Saúde e Acessibilidade (BRASIL, 2014b); e o Plano Nacional dos Direitos da Pessoa com Deficiência - Viver sem Limite de 2011, com novas iniciativas que intensificaram ações em benefício das pessoas com deficiência (BRASIL, 2011a).

Entre outras ações, destaca-se a inauguração, em 2012, do Centro Nacional de Referência em Tecnologia Assistiva - CNRTA com o objetivo de orientar uma rede de núcleos de pesquisa em universidades públicas, estabelecer diretrizes e articular a atuação dos núcleos de produção científica e tecnológica do país; o crédito facilitado para produtos de Tecnologia Assistiva, lançado em 2012 pelo Governo Federal, que tinha como meta financiar a aquisição de produtos de tecnologia assistiva (BRASIL, 2014b); e na área da Saúde, o investimento do Governo Federal na criação de Centros Especializados em Reabilitação (CER) buscando garantir o desenvolvimento de habilidades funcionais das pessoas com deficiência e promover sua autonomia e independência (BRASIL, 2014b).

Além dessas ações, desde 2010 o Ministério de Ciência e Tecnologia MCT em parceria com a Financiadora de Estudos e Projetos -FINEP entre outros parceiros tem investido através de diferentes editais na composição de Núcleos de Pesquisa em Tecnologia Assistiva no país, com o intuito de favorecer iniciativas de desenvolvimento de tecnologias de baixo custo; tecnologias desenvolvidas a partir do conceito de desenho universal, além de produtos que pudessem substituir recursos importados; apoiando projetos cooperativos entre empresas e instituições científicas e tecnológicas com o objetivo de estimular 0 desenvolvimento e a inovação de produtos de Tecnologia Assistiva e desenvolvimento de produtos ou soluções inovadoras que pudessem trazer maior qualidade de vida para as pessoas com deficiência. Ainda em 


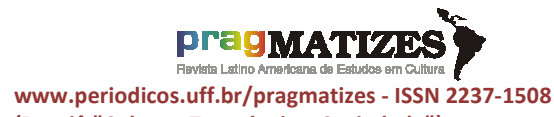

Dossiê "Cultura, Tecnologia e Sociedade")
2013, foi lançada a Chamada Pública CNPq n84/2013 de Tecnologia Assistiva, que teve como foco o apoio financeiro a projetos de pesquisa em Tecnologia Assistiva, com a entrega de produtos ou serviços tecnológicos que pudessem promover a independência e melhorar a qualidade de vida e inclusão social de pessoas com deficiência, ou mobilidade reduzida (BRASIL, 2013b).

Em 2015 aconteceu mais um financiamento na área que foi a chamada da FINEP "Viver Sem Limites", com recursos não reembolsáveis oriundos do Fundo Nacional de Desenvolvimento Científico e Tecnológico (FNDCT) que contemplou 14 projetos com ações de 11 estados do país (FINEP, 2016), além dos estímulos regionais como a Seleção Pública Fapesp e MCTI/FINEP/FNDCT - Propostas para Inovação - PAPPE-PIPE Fase 3 2018, que com recursos orçamentários da FAPESP estimulou projetos de pesquisa para o desenvolvimento de produtos, processos e serviços inovadores, por pequenas empresas paulistas, visando o desenvolvimento de projetos em tecnologia assistiva (FAPESP, 2018).
O conceito oficial de Tecnologia Assistiva, no Brasil, foi elaborado pelo Comitê de Ajudas Técnicas e foi incluído na Lei Brasileira de Inclusão (LBI)/Estatuto da Pessoa com Deficiência (Lei no 13.146, de 6/7/2015) como "produtos, recursos, metodologias, estratégias, práticas e serviços que objetivam promover a funcionalidade, relacionada à atividade e participação, de pessoas com deficiência, incapacidades ou mobilidade reduzida, visando sua autonomia, independência, qualidade de vida e inclusão social" (BRASIL, 2017).

A Lei Brasileira de Inclusãogarantiu à pessoa com deficiência acesso a produtos, recursos, estratégias, práticas, processos, métodos e serviços de Tecnologia Assistiva que ampliassem sua autonomia, mobilidade pessoal e qualidade de vida, e o governo se comprometeu a facilitar o acesso ao crédito especializado; criar mecanismos de fomento à pesquisa e à produção nacional de Tecnologia Assistiva; ampliar o rol de produtos distribuídos no âmbito do SUS; e agilizar, simplificar e priorizar procedimentos de importação de 
tecnologia assistiva - sobre esse último item, o Projeto de Lei no 10.425/2018 vem sendo analisado pela Câmara dos Deputados (CÂMARA DOS DEPUTADOS, 2018).

\section{Tecnologia Assistiva em Ambientes e Produtos Culturais}

Entendendo o ambiente cultural enquanto "agente humanizador" do processo de desenvolvimento do homem e da humanidade, Bruno (2010, p. 124) salienta que "a profunda relação entre o homem e o bem cultural nos contextos culturais, tal como museus, não depende apenas da comunicação das evidências do objeto, mas também do espaço como agente da troca". Essa troca ocorre pela administração, conservação e organização de novas maneiras de informação por meio da elaboração de discursos expositivos e estratégias pedagógicas (BRUNO, 1996).

$\mathrm{Na}$ perspectiva da passagem do sujeito passivo e contemplativo para 0 que age e transforma a sua realidade, preservar o patrimônio cultural aproxima-se cada vez mais de uma nova prática social, ressaltando a importância da inclusão de todos nessa dinâmica (GABRIELE, 2014).
Cury (2009) salienta que o público, o autor e os profissionais da cultura são todos sujeitos desse processo, uma vez que "participam da (re)significação do objeto patrimonial e da circulação da significação" de forma mútua e compartilhada, denotando a dinâmica social relatada nas abordagens para construção do conhecimento. A imaginação é um aspecto importante para a interpretação do público e resulta do seu envolvimento emocional com a obra, mediada também por seus conhecimentos prévios. Assim como o significado da experiência vivida continua no trabalho "imaginativo" do público que o incorpora consigo em sua agenda, experiências e sentimentos.

Araújo (2004, p. 306-307) afirma que

a relação homem a obra/experiência não se constitui apenas em um processo de comunicação, mas de interação informativa, onde o homem se transforma pela apreensão da informação, e o objeto/realidade pela revitalização e ampliação de seu valor simbólico, em um processo contínuo e recíproco, constitutivo e constituidor.

Assim, quando a experiência ocorre de forma eficaz e didática, pode "gerar uma nova dimensão no contexto e tem o seu grau de pertencimento 


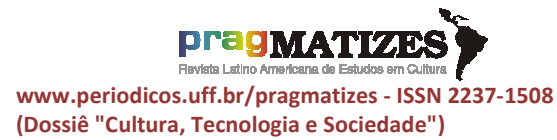

reativado", fortalecendo um dos principais objetivos das instituições culturais: a difusão do conhecimento para instigar a capacidade de reflexão e 0 questionamento (GABRIELE, 2014, p. 46).

Frente aos avanços tecnológicos e às mudanças do público, que se tornou mais diverso e ativo, os ambientes culturais devem seguir novos rumos. Primo (2006) salienta que um novo caminho implica na renovação da apresentação das informações e experiências, adotando linguagens mais diretas, abertas $e$ potencializadoras da reflexão crítica pelo visitante por meio de concepções de ambientes culturais que assumam processos de comunicação mais interativos, que façam apelo aos sentidos, às emoções, às memórias. Para tanto, a interdisciplinaridade é considerada como um instrumento promotor da transformação e, enquanto veículo de comunicação interativa, opera pela apresentação sensível dos objetos expostos, seja em uma linguagem visual, audível ou tátil.

Segundo Neves (2009), para um espaço cultural receber a todos deverá pensar antecipadamente em cada um e nas possíveis interações entre os diversos públicos, onde uma abordagem inclusiva preveja múltiplas soluções, flexíveis e adaptáveis a diferentes situações. Consoante a isto, é essencial compreender o conceito de Tecnologia Assistiva (TA) e os principais recursos e estratégia de acessibilidade que podem ser empregados em ambientes culturais para recepção, experiência e fruição pelo maior número de pessoas em suas diferenças e capacidades.

O maior acesso aos recursos de tecnologia assistiva pessoais como cadeira de rodas, andadores e bengalas, óculos, aparelhos auditivos, recursos de comunicação alternativa ampliam a possibilidade de participação da população nos ambientes culturais, contudo, esses espaços necessitam desenvolver uma série de estratégias para favorecer a fruição.

Entre as soluções mais empregadas em ambientes culturais, destacam-se: os audioguias, enquanto sistema eletrônico de tour personalizado; Língua Brasileira de Sinais - LIBRAS para Surdos e Legendas descritivas para Surdos e Ensurdecidos (LSE); Recursos táteis, que podem englobar maquetes táteis, 


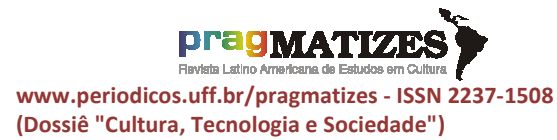

(Dossiê "Cultura, Tecnologia e Sociedade") taxidermia, réplicas e toque em artefatos originais tais como artefatos arqueológicos; a audiodescrição, enquanto tradução das informações e mensagens visuais no meio sonoro; o texto ampliado, como recurso às pessoas com visão residual, como as pessoas com baixa visão; o Braille, enquanto sistema de escrita com pontos em relevo; e o closed caption, como sistema de transmissão de legendas que descreve os sons e falas presentes nas imagens e cenas.

Outras soluções menos usuais, mas igualmente importantes, envolvem os Sistemas de Comunicação Aumentativa e Alternativa, enquanto formatos para comunicação com diferentes públicos, principalmente pessoas com dificuldades de se comunicar por meio da fala ou da escrita; o texto simples, que traduz conteúdos complexos dos diferentes equipamentos culturais considerando as necessidades das pessoas com deficiência intelectual, e pessoas com dificuldades de leitura, ou que não têm o Português como primeira língua; o texto apoiado por pictogramas que tem o objetivo de facilitar a compreensão do conteúdo a ser transmitido; o uso do QRCode como dispositivo de ampliação das informações de acessibilidade como a audiodescrição de uma imagem, ou a apresentação de informações em áudio ou como um vídeo em Libras; e o uso de dispositivos de alta tecnologia como computadores, comunicadores e dispositivos móveis como facilitadores do processo de fruição estética. Assim, novas estratégias e recursos começam a ser empregadas para aproximação ao público geral por meio de novas oportunidades de percepção.

Um espaço cultural pode receber pessoas que tenham dificuldades comunicativas e, por essa razão, é fundamental que haja pranchas de comunicação disponíveis que possibilitem ao visitante fazer perguntas, comentários e escolhas dentro daquele espaço. Para oferecer o acesso à "Exposição Cidade Acessível", que aconteceu na Casa da Ciência da UFRJ, foram elaboradas 34 pranchas impressas. As pranchas de comunicação foram organizadas a partir dos diferentes espaços da exposição como a "entrada", a "praça", o "ônibus" e a "escola" (PELOSI et al., 2015).

Sabe-se que somente a implementação das tecnologias 


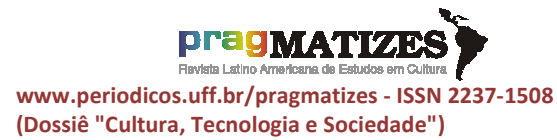

(Dossiê "Cultura, Tecnologia e Sociedade") assistivas não é suficiente para garantir a qualidade de fruição cultural das pessoas com deficiência os produtos culturais. As dimensões de acessibilidade arquitetônica, comunicacional e instrumental devem ser acompanhadas de iniciativas de acessibilidades atitudinais e metodológicas a fim de romper as barreiras e buscar alternativas que qualifiquem o conforto, a inclusão, a convivência em diversidade, a autonomia para a real participação da pessoa com deficiência no uso e no consumo dos produtos culturais. Desta forma, cabe aos gestores dos diferentes ambientes culturais buscar informação e capacitação de sua equipe para a qualificação do atendimento a este público, bem como ampliar a participação de profissionais da área para colaborar na construção de programas e projetos culturais acessíveis. Do mesmo modo, se faz necessário que a implementação de tais iniciativas se comprometa a atender a diversidade das deficiências. Sem dúvida, esta não é uma tarefa fácil e se torna urgente que comprometidos com uma políticacultural afinada com a promoção da diversidade cultural estejamos mais atentos ao público com deficiência.

É importante destacar que os avanços da obrigatoriedade de acessibilidade nos produtos culturais, seja pelo avanço do debate e das conquistas no âmbito das políticas culturais ou pela LBI tem provocado uma rede de contatos e ampliado o diálogo qualificado entre os trabalhadores culturais, profissionais de diferentes áreas que atuam na promoção da inclusão e pessoas com deficiência. Nesta aproximação observa-se que um significativo número de profissionais da área cultural tem buscado formação não só para qualificar seus projetos culturais em função de atender a legislação, mas também para incorporar as diferentes tecnologias assistivas como recurso de linguagem de sua obra artística. Do mesmo modo, um conjunto de pessoas com deficiência tem se qualificado para atuar como mediadores nos ambientes culturais e consultores de implementações de projetos acessíveis. Entre estas iniciativas destaca-se audiodescrição, uma área identificada no campo da tradução e considerada uma tecnologia assistiva que tem 
crescido com rapidez no mercado brasileiro e que de forma qualificada exige-se um consultor com deficiência visual e de preferência com formação na área da audiodescrição para atuar na elaboração dos roteiros audiodescritos para diferentes áreas. Neste contexto, observa-se que se amplia o número de pessoas da área cultural atentas às orientações da luta das pessoas com deficiência que nos provocam a atualização constante através da perspectiva do modelo social da deficiência e sua luta legitimada no tema "Nada sobre nós sem nós".

Sabe-se que a partir da obrigatoriedade da inclusão de recursos acessíveis nos projetos financiados pela Lei Rouanet ampliaram-se em escala significativa as diferentes iniciativas culturais acessíveis no país. As iniciativas de acessibilidade geralmente até então encontradas em grandes centros culturais ou museus agora se estendem a espetáculos das diferentes áreas artísticas, tornando-se comum a presença do intérprete de libras em diferentes shows e até 0 uso de mochilas áudio táteis e piso vibratório para uso da comunidade surda que possibilita a dimensão física da experiência musical. A incorporação da obrigatoriedade nas iniciativas da Lei Rouanet fez também com que o MinC fosse gradualmente incorporando para o seu quadro de pareceristas perfil qualificado para avaliação dos quesitos de acessibilidade.

Do mesmo modo, cabe aqui destacar o pioneirismo do Brasil na área do audiovisual tanto no que diz respeito a produção cinematográfica com acessibilidade bem como da obrigatoriedade de as3.336 salas de cinema do país oferecerem recursos de acessibilidade cultural para pessoas com deficiência auditiva e visual. Após a MP 917/19 que adiou até janeiro de 2021 a IN 128/2016 da Ancine, todos os exibidores deverão oferecer legendagem, legendagem descritiva, audiodescrição e Libras para quem solicitar.Filmes nacionais com financiamento público ou não e filmes internacionais já são produzidos com os recursos de acessibilidade para exibição no Brasil. A iniciativa brasileira tem provocado a política internacional da produção e exibição audiovisual para os quesitos de acessibilidade. $\quad \mathrm{Na}$ produção 


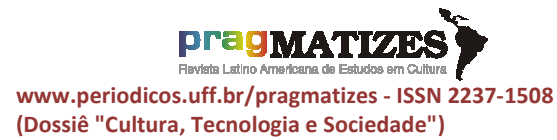

(Dossiê "Cultura, Tecnologia e Sociedade") audiovisual para TV brasileira já se observa o número crescente da produção audiovisual acessível que tem cumprido a legislação.

No âmbito da política do Livro e Leitura há muito o que se fazer. $O$ tratado de Marraqueche, tem como objetivo possibilitar a criação de cópias de obras em formatos acessíveis e permite aos países signatários adotarem o intercâmbio transfronteiriço dessas obras por intermédio de entidades autorizadas. Muitas questõesproblematizadoras surgem a partir do tratado, entre elas destacamse: de autorização de algumas entidades selecionadas para tal atividade concentrando esta produção; a autonomia da pessoa com deficiência visual em poder escolher a obra a que quer ter acesso; a atualização das iniciativas que ampliam o direito cultural das pessoas com deficiência a leitura através de livros multiformatos que atendem diferentes deficiências e a própria LBI, no capítulo $9 \S 1$ que ao destacar que "É vedada a recusa de oferta de obra intelectual emformato acessível à pessoa com deficiência, sob qualquer argumento, inclusive sob a alegação de proteção dos direitos de propriedade intelectual" coloca em questão 0 papel das editoras na produção de obras acessíveis para diferentes públicos.

$$
\text { É fundamental ampliar os }
$$
recursos destinados à implementação dos recursos de acessibilidade para os projetos e produtos culturais. $\mathrm{O}$ pouco conhecimento dos gestores públicos sobre a demanda tem sido representado no baixo orçamento para tal, o que tem dificultado para o realizador cumprir suas metas de acessibilidade com qualidade nos seus produtos culturais. É urgente a aproximação dos trabalhadores e gestores culturais ao conhecimento da demanda de acessibilidade cultural, bem como aos serviços a serem contratados. A qualidade dos serviços é fundamental para a fruição do público com deficiência. Do mesmo modo, é hora também de as pessoas com deficiência ampliarem sua visibilidade como público e plateianas atividades culturais acessíveis, bem como os ambientes culturais atuarem com a formação de público com esta população. 


\section{Considerações finais}

Tais reflexõesreiteram importância de considerar os direitos culturais da pessoa com deficiência e a perspectiva inclusiva na medida em que os espaços e as mentalidades são alterados para considerar as mediações comunicacionais diversas, e também, a necessidade de retomada de investimentos públicos no desenvolvimento de pesquisa em acessibilidade e no fortalecimento dos Núcleos de Pesquisa em Tecnologia Assistiva e $\quad 0$ correlato desenvolvimento de grupos e redes de pesquisa, especialmente, entre as Instituições Públicas de Ensino Superior.

Importante salientar que os recursos e estratégias de tecnologia assistiva que são empregados com o foco nas pessoas com deficiência, podem ser facultados a todos. Assim, proporcionando experiências únicas, uma vez que os sentidos podem ser estimulados de outras maneiras, considerando as vivências dos mais diversos públicos ao respeitar suas diferenças, potencializando suas experiências e promovendo a inclusão. O apelo à experiência multissensorial e à interatividade também conduz a soluções lúdico-pedagógicas muito apreciadas pelo público infantil, que pode ter a oportunidade de atuar ativamente (NEVES, 2009).

Uma abordagem multissensorial visa fundamentalmente a inclusão pela oferta de experiências em distintos níveis de complexidade e por diversos recursos e meios de comunicação para todos, levando em consideração as capacidades e eficiências de um público mais diverso e as possibilidades de interação entres diferentes públicos em um mesmo espaço. Tal perspectiva, alinha-se à compreensão expansiva da Tecnologia Assistiva como área interdisciplinar, a qual não se reduz ao paradigma clínico-médico centrando-se apenas na adaptação individual, levando em conta, sobretudo, o caráter dialógico das interações sociais em diversas esferas, como por exemplo, a artística e a cultural.

Um caminho longo já foi percorrido, mas o desafio de qualificar a aproximação do uso da tecnologia assistiva nos ambientes e produtos culturais nos convoca não só a ampliar as experiências interdisciplinares, mas ao aprofundamento em pesquisa da aplicabilidade destes recursos no bom 


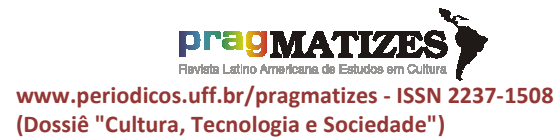

(Dossiê "Cultura, Tecnologia e Sociedade") uso dos processos de mediação e consumo do produto cultural. Neste sentido se faz necessário ampliar a sensibilização dos gestores públicos de cultura e os diversos atores do campo para o conhecimento técnico destas tecnologias que atuam no processo de participação e autonomia das pessoas com deficiência. Cabe à universidade pública e ao setor público cultural, bem como à sociedade civil, atuarem juntos na busca de recursos viabilizando a continuidade da promoção da cidadania cultural das pessoas com deficiência explícita já nos compromissos da política pública cultural e na LBI, entre outros.

Em tempos de pandemia de COVID 19 observou-se a mobilização mundial de artistas e gestores de ambientes culturais na difusão de suas obras e conteúdos culturais através de diferentes recursos tecnológicos. Raríssimas foram as "lives" e visitas a acervos de forma virtual que ofereceram os recursos de acessibilidade para a população com deficiência. Com certeza, estes tempos de reclusão serão expandidos e traduzidos em novas iniciativas que com 0 tempo aperfeiçoarão os recursos de mediação cultural. As tecnologias assistivas e as pessoas com deficiência devem ser inseridas com qualidade como público e plateia participando em pé de igualdade com os demais na construção deste novo momento histórico da humanidade.

\section{Referências bibliográficas:}

ARAÚJO, Marcelo M. Comunicação Museológica: desafios e perspectivas. In: Anais do Seminário de Capacitação museológica. Belo Horizonte: Instituto Cultural Flávio Gutierrez, 2004. p. 304-314.

BRASIL. DECRETO № 7.612, de 17 de novembro de 2011 que institui o Plano Nacional dos Direitos da Pessoa com Deficiência - Plano Viver sem Limite (2011a). Disponível em http://www.planalto.gov.br/ccivil_03/_At o2011-2014/2011/Decreto/D7612.htm. Acesso: 22 jul. 2016.

BRASIL. Financiadora de Estudos e Pesquisas - FINEP. Chamada MCTISECIS/CNPQ no 84/2013 - tecnologia assistiva. (2013a). Disponível em: http://resultado.cnpq.br/809787424357 2530. Acesso: 20 mar. 2020.

BRASIL. Financiadora de Estudos e Projetos - FINEP. Chamada pública MCT/FINEP - ação transversal tecnologia assistiva - 01/2010. Disponível em: http://www.finep.gov.br/chamadaspublicas/chamadapublica/569. Acesso: 20 mar. 2020.

BRASIL. Financiadora de Estudos e Projetos - FINEP. Chamada pública MCTI/SECIS/FINEP/FNDCT cooperação empresa-ICT - tecnologia assistiva - 01/2011. (2011b). Disponível em: 


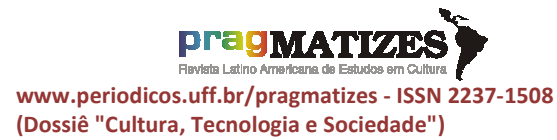

http://coral.ufsm.br/prpgp/images/editai s-externos/ChamadaPublica-Assistiva2011-ICT-Empresa-29-12-2011.pdf.

Acesso: 30 mar. 2020.

BRASIL. Financiadora de Estudos e Projetos - FINEP. Chamada pública MCTI/SECIS/FINEP/FNDCT

cooperação ICT-empresa - tecnologia assistiva - 01/2013. (2013b). Disponível em: https://docplayer.com.br/18925861Chamada-publica-mcti-secis-finepfndct-cooperacao-ict-empresatecnologia-assistiva-01-2013.html. Acesso: 30 mar. 2020.

BRASIL. Financiadora de Estudos e Projetos - FINEP. Edital Viver sem Limites. Disponível em: http://www.finep.gov.br/noticias/todasnoticias/5260-finep-divulga-resultadodo-edital-viver-sem-limites. Acesso: 4 ago. 2016.

BRASIL. Ministério da Educação e Cultura. Programas do MEC voltados à formação de professores, 2014a. Disponível em: http://portal.mec.gov.br/index.php?opti on=com content\&view=article\&id=15944:progra mas-do-mec-voltados-a-formacao-deprofessores. Acesso: 20 mar. 2020.

BRASIL. Observatório Municipal da Pessoa com Deficiência, 2014b. Disponível em: https://www.prefeitura.sp.gov.br/cidade /secretarias/pessoa_com_deficiencia/o bservatorio municipal da pessoa co $m \_$deficiencia/index.php? $p=274862$.

Acesso: 25 mar. 2020.

BRASIL. PORTARIA NORMATIVA №13, DE 24 DE ABRIL DE 2007. Dispõe sobre a criação do Programa de. Implantação de Salas de Recursos (2007). Disponível em: portal.mec.gov.br/docman/fevereiro- 2012-pdf/9935-portaria-13-24-abril2007. Acesso: 20 mar. 2016.

BRUNO, M. C. O. (coord.); ARAUJO, M. M.; COUTINHO, M. I. L. (col.). A evidência dos contextos museológicos. In: Waldisa Rússio Camargo Guarnieri: textos e contextos de uma trajetória profissional. São Paulo: Pinacoteca; ICOM, 2010. v. 1.

BRUNO, Maria Cristina Oliveira. Museologia e comunicação. Cadernos de Sociomuseologia, Lisboa, Universidade Lusófona de Humanidades e Tecnologias, n. 9, 1996.

CÂMARA DOS DEPUTADOS. Projeto de Lei no 10.425/2018 que isenta de IPI produtos de tecnologia assistiva destinados às pessoas com deficiência sob a autoria do deputado Lindomar Garçon (PRB-RO). Disponível em: https://www2.camara.leg.br/camaranoti cias/noticias/direitos-humanos/564673projeto-isenta-de-ipi-produtos-detecnologia-assistiva-destinados-aspessoas-com-deficiencia.html. Acesso: 22 mar. 2020.

CURY, Marília X. O sujeito do Museu. MUSAS - Revista Brasileira de Museus e Museologia, Rio de Janeiro, Instituto Brasileiro de Museus n. 4, p. 86-97, 2009.

DORNELES, Patrícia et al. Do direito cultural das pessoas com deficiência. Revista de Política Públicas da UFMA, v. 22, p. 138, 2018.

DORNELES, Patrícia S.; CARVALHO, Claudia R. A. de; MEFANO, Vânia. Breve histórico da acessibilidade nas políticas culturais no Brasil. Anais do XV ENECULT. Salvador:UFBA, 2019.

DUPIN, G. Dez anos da Convenção da Diversidade. In: KAUARK, Giuliana; BARROS, José Márcio Barros; MIGUEZ, Paulo (orgs.). Diversidade 
Cultural: políticas, visibilidades midiáticas e redes. Salvador: EDUFBA 2015.

FAPESP. Fundação de Amparo à Pesquisa do Estado de São Paulo. Seleção Pública Fapesp e MCTI/FINEP/FNDCT - Propostas para Inovação - PAPPE-PIPE Fase 3 2018. Disponível em: http://www.fapesp.br/11554. Acesso: 29 mar. 2020.

FRANÇA JR, Luis Celestino de; .LIMA, Yasmin Gonçalves; RODRIGUES, Thiago. A Cultura na Universidade. Memórias da Pró-Reitoria de Cultura da Universidade Federal do Cariri. Anais do XIV ENECULT. Salvador, UFBA, 2018.

FREIRE, Paulo. Ação cultural para a liberdade. Rio de Janeiro: Paz e Terra, 1981.

GABRIELE, Maria Cecília Figueiras Lima. Sociomuseologia: uma reflexão sobre a relação museus e sociedade. Expressa Extensão, Pelotas, Universidade Federal de Pelotas, vol. 19 n. 2, 2014.

MELO, Francisco Ricardo Lins Vieira de; ARAUJO, Eliana Rodrigues. Núcleos de Acessibilidade nas Universidades: reflexões a partir de uma experiência institucional. Psicol. Esc. Educ. [online], vol.22, n. spe, p.57-66, 2018.

NEVES, Josélia. Comunicação multisensorial em contexto museológico. Actas do 1 Seminário de Investigação em Museologia dos países de língua portuguesa e espanhola. Vol. 2, p 180192, 2009.

PASSERINO, L. M. A tecnologia assistiva na política pública brasileira e a formaçãode professores: que relação é essa? In: BAPTISTA, C. R. (org.). Escolarização e deficiência: configurações nas políticas de inclusão escolar. São Carlos: Marquezine \& Manzini: ABPEE, 2015. p. 189-203.

PELOSI, M.B. et al. A Comunicação Alternativa na Exposição Cidade Acessível da Casa da Ciência. In: VI Congresso Brasileiro de Comunicação Alternativa Isaac Brasil, 2015, Campinas. Anais [....]. Marília: ABPEE, 2015.

PRIMO, Judite. Museologia e Design na construção de objetos comunicantes. Caleidoscópio Revista de Comunicação e Cultura do Departamento de Ciências da Comunicação, Artes e Tecnologias da Informação da Universidade Lusófona de Humanidades e Tecnologias (ULHT), Portugal, 2006.

RUBIM, Albino Canelas. A. Universidade, cultura e políticas culturais. Revista de Educação Popular, p. 6-17, 4 jun. 2019.

SARRAF, Viviane Panelli. Comunicação dos Cinco Sentidos em Espaços Culturais. Cisc 20 anos, v. 1, p. 107-118, 2012. 